\title{
AVALIAÇÃO DE COMPONENTES BIOATIVOS EM SUCO MISTO DE FRUTAS E HORTALIÇA DURANTE 100 DIAS DE ARMAZENAMENTO
}

\section{ASSESSMENT OF BIOACTIVE COMPONENTS IN BLEND BY FRUITS AND VEGETABLE DURING 100 DAYS OF STORAGE}

\author{
Roberta de Souza Leone ${ }^{1}$, Afonso Mota Ramos ${ }^{2}$, Fernanda Izabel Garcia da Rocha ${ }^{3}$ \\ ${ }^{1}$ Universidade Federal do Paraná - UFPR - Curitiba robertasleone@ gmail.com \\ ${ }^{2}$ Universidade Federal de Viçosa - UFV - Viçosa amramos@ufv.br \\ ${ }^{3}$ Universidade Estadual do Mato Grossa do Sul - UEMS - Naviraí fernanirocha@yahoo.com.br
}

\begin{abstract}
Resumo
O suco misto composto de 21,8\% de polpa de uva, $14 \%$ de polpa de azedinha e 4,2\% de polpa de acerola, foi avaliado quanto à atividade antioxidante e aos teores de luteína, compostos fenólicos e vitamina $C$, durante 100 dias de armazenamento. Os teores de vitamina $C$ e de compostos fenólicos diminuíram, porém a atividade antioxidante e o teor de luteína permaneceram iguais, indicando que a luteína é o principal composto responsável pela atividade antioxidante do suco misto, justificando o uso de polpa de hortaliças em sucos. Após 100 dias de armazenamento, o suco misto possuía boa atividade antioxidante, mantendo suas propriedades bioativas de auxílio na prevenção de doenças causadas pelos radicais livres.
\end{abstract}

Palavras-chave: suco misto; luteína; vitamina C; atividade antioxidante.

\section{Introdução}

O Brasil é um grande exportador de produtos do agronegócio e a arrecadação com esses produtos cresce a cada ano. Com clima privilegiado e território fértil disponível, o Brasil produz as mais variadas espécies de frutas tropicais, sendo parte da produção destinada à indústria de sucos de frutas, que correspondeu à cerca de 4\% do total das exportações do agronegócio brasileiro em 2007 (BRASIL, 2007).

Enquanto o valor do mercado internacional de frutas frescas em 2006 estava em torno de US \$23 bilhões, o valor dos produtos processados a partir das frutas correspondia a US\$90 bilhões, destacando a importância da agregação de valor na fruticultura através do processamento (VILELA e ARAUJO, 2006). 
Estima-se que a produção atual de hortaliças no Brasil seja superior a 11 milhões de toneladas com um valor aproximado de 2,5 bilhões de dólares (NASCIMENTO, 2009). No mercado de hortaliças, o excesso de oferta tende a ocasionar queda acentuada de preços, o que acarreta prejuízos aos produtores e problemas para a situação econômica dos municípios onde essas atividades são importantes. A olericultura (cultura de hortaliças) é o ramo da horticultura que tem o maior número de cultivares explorados, possuindo características marcantes, como ciclo curto, alta produtividade, e está inserida em um contexto de mercado dinâmico (CAMARGO FILHO e MAZZEI, 1994). A produção de polpa e/ou sucos compostos de hortaliças seria uma alternativa para aproveitar o excedente da produção de hortaliças, diminuindo o prejuízo dos produtores causado pela queda dos preços durante a safra e, ainda, proporcionar ao produtor a possibilidade de comercializar o seu produto durante o ano todo.

Os sucos de frutas são apreciados não só pelo sabor agradável, mas também, pelas suas propriedades nutritivas e funcionais. As vitaminas são os componentes bioativos mais importantes da maioria das frutas, porém encontramos também benefícios nos compostos fenólicos, nos carotenóides e, conseqüentemente, na atividade antioxidante produzida por estes compostos. Os sucos mistos estão entrando no mercado pelo desenvolvimento de novos sabores e pela possibilidade de enriquecimento do valor nutritivo e funcional do suco.

O órgão responsável pela regulamentação de produtos de origem vegetal no Brasil é o Ministério da Agricultura, Pecuária e Abastecimento (MAPA). A Lei no 8918 do MAPA define suco misto como o suco obtido pela mistura de duas ou mais frutas e das partes comestíveis de dois ou mais vegetais, ou dos seus respectivos sucos, sendo a denominação constituída da palavra suco, seguida da relação de frutas e vegetais utilizados, em ordem decrescente das quantidades presentes na mistura (BRASIL, 1994).

A legislação brasileira para suco tropical estabelece a quantidade mínima de $50 \%(\mathrm{~m} / \mathrm{m})$ de polpa para compor o suco pronto para beber, ressalvado o caso de fruta com acidez alta ou conteúdo de polpa muito elevado ou sabor muito forte que, neste caso, o conteúdo de polpa não deve ser inferior a $35 \%(\mathrm{~m} / \mathrm{m})($ BRASIL, 2003).

Atualmente existe um grande interesse no estudo dos antioxidantes devido, principalmente, às descobertas sobre o efeito dos radicais livres no organismo. A oxidação é parte fundamental da vida aeróbica e do nosso metabolismo e, assim, os radicais livres são produzidos naturalmente ou por alguma disfunção biológica (BARREIROS et al., 2006). O envelhecimento da célula, dos tecidos e do organismo como um todo, é uma ação destes radicais livres, que por possuírem um elétron livre na última camada são muito instáveis e reativos. Para se estabilizar eles podem ganhar um elétron (reação de redução) ou perder um elétron (reação de oxidação). Os seus efeitos sobre o organismo são, de maneira geral, nocivos e estão relacionados há cerca de 60 condições clínicas, 
entre elas a catarata, a aterosclerose, o câncer, isquemia e alterações no sistema nervoso (LANGSETH, 1995).

Os responsáveis pelo combate à ação nociva dessas substâncias no organismo são os varredores de radicais livres ou antioxidantes (SILVA 2003). Os antioxidantes atuam em diferentes níveis na proteção dos organismos. O primeiro mecanismo de defesa contra os radicais livres é impedir a sua formação, principalmente pela inibição das reações em cadeia com o ferro e o cobre. Eles são capazes de interceptar os radicais livres gerados pelo metabolismo celular ou por fontes exógenas, impedindo o ataque sobre os lipídeos, os aminoácidos das proteínas, a dupla ligação dos ácidos graxos poliinsaturados e as bases do DNA, evitando a formação de lesões e perda da integridade celular. Os antioxidantes obtidos da dieta, tais como as vitaminas $\mathrm{C}, \mathrm{E}$ e A, os polifenóis e carotenóides são extremamente importantes na interceptação dos radicais livres (BIANCH e ANTUNES, 1999)

A vitamina $\mathrm{C}$ é hidrossolúvel e termolábil. Os seres humanos e outros primatas são os únicos mamíferos incapazes de sintetizá-la (NISHIKIMI et al., 1994). Considerada um excelente antioxidante, os benefícios obtidos na utilização terapêutica da vitamina $\mathrm{C}$ em ensaios biológicos com animais incluem o efeito protetor contra os danos causados pela exposição às radiações e medicamentos (AMARA-MOKRANE et al., 1996). A vitamina C participa dos processos celulares de oxi-redução, previne o escorbuto, é importante na defesa do organismo contra infecções e fundamental na integridade das paredes dos vasos sangüíneos (MANELA-AZULAY et al., 2003).

Os possíveis efeitos anticarcinogênicos da vitamina $\mathrm{C}$ estão relacionados com sua habilidade em detoxicar substâncias carcinogênicas e por sua atividade antioxidante (STAHL e SIES, 1997). Além disso, tem-se constatado que a vitamina $\mathrm{C}$ pode inibir a formação de nitrosaminas in vivo a partir de nitratos e nitritos usados como conservantes, sendo adicionada a muitos produtos alimentares industrializados para prevenir a formação desses compostos reconhecidamente carcinogênicos (KUHN et al.,1991; BIANCHI e ANTUNES, 1999). As maiores fontes alimentares são as frutas, especialmente a acerola, o caju e a goiaba, e hortaliças como brócolis, couve e couveflor.

Os compostos fenólicos são produtos do metabolismo secundário das plantas (SÁNCHEZMORENO, 2002). Alimentos comuns, como uva e seus produtos derivados, contêm uma grande variedade de compostos fenólicos em quantidades variando de traços a alguns gramas por quilograma do alimento fresco. Tem sido relatado que estes compostos possuem múltiplos efeitos biológicos como atividade antioxidante, ação antiinflamatória, inibição da agregação de plaquetas nos vasos sanguíneos e atividade antimicrobiana (MAZZA et al., 1999). Incluem-se, principalmente, na categoria de seqüestradores de radicais livres (HASLAM, 1996; SOARES, 2002), ainda que também possam exercer sua ação antioxidante através de outros mecanismos, 
como quelantes de íons metálicos que catalisam reações de oxidação. Esses compostos interferem na oxidação dos lipídeos e de outras moléculas por uma rápida doação de um átomo de hidrogênio aos radicais livres. Os radicais fenóxidos formados são intermediários bastante estáveis (ressonância com o anel benzênico) e dificilmente iniciam uma nova reação em cadeia. Esses radicais intermediários fenóxidos atuam reagindo com outros radicais livres, culminando com a terminação das reações de propagação (SÁNCHEZ-MORENO, 2002).

A luteína é um carotenóide encontrado em frutas e, principalmente, hortaliças verdes. Estudos epidemiológicos recentes demonstram uma associação entre elevados níveis de carotenóides na dieta ou no sangue e um efeito protetor contra o desenvolvimento de doenças crônicas, como certos tipos de câncer, doenças cardiovasculares, doenças degenerativas da mácula e cataratas (EDGE et al., 1997).

De todos os carotenóides presentes no plasma humano, luteína e zeaxantina são os dois encontrados em maior quantidade no globo ocular, mais especificamente na área central da retina e na mácula, constituindo o pigmento macular (PM). Eles são responsáveis pela coloração amarela na região da retina (BEATTY et al., 2004). A luteína é considerada o antioxidante predominante no olho, protegendo os tecidos da oxidação ao filtrar a luz azul e ao neutralizar os radicais livres. A mácula é um dos tecidos mais metabolicamente ativos de todo o organismo, tem grande concentração de ácidos graxos polinsaturados, é bastante susceptível a danos, e possui baixa capacidade de regeneração (DAVIES e MORLAND, 2004).

A degeneração macular relacionada à idade (DMRI) é a principal causa de perda de visão irreversível na população de idade avançada nos EUA e no mundo Ocidental. Dados do Conselho Brasileiro de Oftalmologia estimam que, aproximadamente, 2,9 milhões de brasileiros com mais de 65 anos de idade apresentam casos de DMRI. Essa doença ocular, grave e irreversível, causa cegueira em pessoas na faixa etária acima de 65 anos. Com o aumento da expectativa de vida é natural que o número de casos se eleve, tornando o impacto da DMRI na saúde pública mais severo (LAJOULO, 2004; MOZZAFARIEH et al., 2003).

Uma vez estabelecida a degeneração macular, não há retorno à visão normal, mesmo com o incremento desses carotenóides na dieta. Quando há suplementação de luteína ou zeaxantina após o início do quadro, ocorre apenas uma diminuição ou estabilização na perda progressiva da visão. $\mathrm{O}$ efeito protetor pode ser explicado pelo acúmulo seletivo destes carotenóides na retina e por sua densidade na mácula (LANDRUM et al., 1997; BERENDSCHOT et al., 2000). A luteína, não é sintetizada pelo organismo, sendo necessário que ela seja suprida pela ingestão alimentar (DAVIES e MORLAND, 2004).

O objetivo deste trabalho foi avaliar, ao longo de 100 dias, a propriedade antioxidante e os teores de luteína, vitamina $\mathrm{C}$ e compostos fenólicos de suco misto de uva, acerola e azedinha. 


\section{Material e Métodos}

$\mathrm{Na}$ formulação do suco misto, foram utilizadas polpas das frutas uva e acerola, industrializadas e pasteurizadas pela empresa Bela Ischia, juntamente com a polpa da hortaliça azedinha (Rumex acetosa), produzida no laboratório. As folhas de azedinha foram higienizadas e sanitizadas em água clorada a $150 \mathrm{mg} \mathrm{L}^{-1}$ de cloro residual livre e sua polpa foi extraída em uma centrífuga Walita, modelo R1 1861. Em seguida foi peneirada, pasteurizada a $90^{\circ} \mathrm{C} 60 \mathrm{~s}^{-1}$ (FREITAS et al., 2006a), envasada à quente em garrafas de vidro esterilizadas por 30 minutos em água fervente, resfriada em água corrente e congelada até posterior utilização.

O suco foi formulado com polpas de uva $(21,8 \%)$, acerola $(4,2 \%)$ e azedinha $(14 \%)$ e o teor de sólidos solúveis ajustado para $14^{\circ}$ Brix com sacarose. Adicionou-se os conservantes benzoato de sódio (260 mg L $\mathrm{m}^{-1}$ ) e metabissulfito de sódio (40mg SO $\mathrm{L} \mathrm{L}^{-1}$ ). Em seguida, o suco foi pasteurizado a

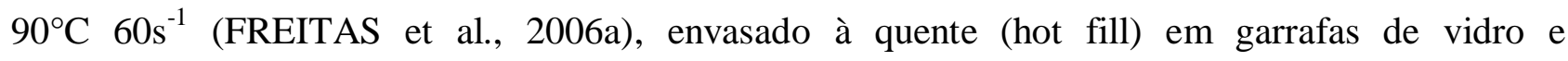
armazenados a temperatura ambiente.

A luteína foi extraída seguindo metodologia descrita por Nachtigall (2007), utilizando acetona como solvente extrator. A quantificação do teor de luteína foi efetuada por Cromatografia Líquida de Alta Eficiência (CLAE) de acordo com Nunes e Mercadante (2004), com coluna de fase reversa $\mathrm{C}_{30} \mathrm{YMC}$, fase móvel metanol (0,1\% de trimetilamina/ metil-terc-butil éter 95:5) e fluxo de $1 \mathrm{~mL} \min ^{-1}$ em modo isocrático, injeção de $50 \mu \mathrm{L}$ e leitura em comprimento de onda de $450 \mathrm{~nm}$.

As condições para extração e análise da vitamina $\mathrm{C}$ seguiram as condições desenvolvidas por Campos (2006). A quantificação de vitamina C no suco foi realizada por Cromatografia Líquida de Alta Eficiência (CLAE), RP-18; detector espectrofotométrico de arranjos de diodos, fase móvel água ultrapura contendo $1 \mathrm{mM}$ de fosfato monobásico de sódio, $1 \mathrm{mM}$ de EDTA e pH ajustado para 3,0 com ácido fosfórico, com fluxo de $1,0 \mathrm{~mL} \mathrm{~min}^{-1}$ e leitura em comprimento de onda de $245 \mathrm{~nm}$ (CAMPOS, 2006).

$\mathrm{Na}$ determinação dos compostos fenólicos seguiu-se a metodologia do reagente de FolinDenis, modificada por Silva (2003). O solvente extrator utilizado foi acetona:água (70:30). A quantidade de polifenóis totais foi calculada com base na curva padrão de ácido gálico P.A. preparada com soluções do padrão variando entre 0 e $170 \mathrm{mg} \mathrm{L}^{-1}$. O conteúdo fenólico total foi expresso em AGE (ácido gálico equivalente).

A determinação da atividade antioxidante foi realizada seguindo a metodologia de avaliação da capacidade sequestrante de radicais 2,2-difenil-1-picrilhidrazil (DPPH'), descrita por Espín et al. (2000) e Pukalskas et al. (2002) com modificações, sendo analisada a porcentagem de moléculas do radical DPPH seqüestrado, após determinado tempo, pelos extratos a $50 \mathrm{ppm}$ de polifenóis 
expressos em AGE. . Foi previamente preparada uma solução etanólica 95\% de DPPH (0,1mM) e misturada em cubeta de vidro com extratos fenólicos do suco misto nas proporções de 3,5 para 0,5 respectivamente, em temperatura ambiente. A absorbância foi lida em $517 \mathrm{~nm}$ em espectrofotômetro no tempo zero e após 7 minutos de reação, no escuro e à temperatura ambiente. A quantificação foi realizada de acordo com a Equação 1, onde ( $\left.\mathrm{DPPH}^{*}\right)_{\mathrm{f}}$ é a absorbância medida no tempo 7 minutos e $\left(\mathrm{DPPH}^{\circ}\right)_{\mathrm{o}}$ a absorbância medida no tempo zero.

$$
\% \text { atividade sequestrante }=\left[1-\left(\mathrm{DPPH}^{*}\right)_{\mathrm{f}} /\left(\mathrm{DPPH}^{*}\right)_{\mathrm{o}}\right] \times 100
$$

O processamento do suco se realizou em três repetições conforme delineamento estatístico. Todas as determinações foram realizadas nos tempos zero, 20, 40, 60, 80 e 100 dias de armazenamento. Os dados experimentais foram processados por regressão em termos de valores de F $(p<0,01)$ utilizando o Programa SAEG 9.1, licenciado pela UFV.

\section{Resultados e Discussão}

Na Tabela 1 encontram-se as médias aritméticas e desvio padrão de 3 repetições das respostas obtidas nas análises de luteína, vitamina $\mathrm{C}$, compostos fenólicos e atividade antioxidante.

Tabela 1 - Valores médios dos compostos bioativos: luteína, vitamina C e fenólicos e da \% atividade sequestrante

\begin{tabular}{lcccc}
\hline Tempo & $\begin{array}{c}\text { Luteína }^{\text {ms }} \\
\mathbf{m g / 1 0 0 m L}\end{array}$ & $\begin{array}{c}\text { Vitamina C** } \\
\mathbf{m g} / \mathbf{1 0 0 g}\end{array}$ & $\begin{array}{c}\text { Fenólicos** } \\
\text { mgAGE/100mL }\end{array}$ & $\begin{array}{c}\text { \% Atividade } \\
\text { antioxidante }^{\text {ns }}\end{array}$ \\
\hline 0 & $0,033 \pm 0,07$ & $20,29 \pm 0,31$ & $39,83 \pm 4,11$ & $61,9 \pm 3,48$ \\
20 & $0,039 \pm 0,16$ & $22,48 \pm 0,39$ & $35,20 \pm 0,74$ & $63,9 \pm 4,49$ \\
40 & $0,033 \pm 0,16$ & $19,16 \pm 2,86$ & $35,03 \pm 2,34$ & $53,5 \pm 10,16$ \\
60 & $0,043 \pm 0,12$ & $8,80 \pm 1,73$ & $33,99 \pm 3,34$ & $75,1 \pm 19,72$ \\
80 & $0,036 \pm 0,18$ & $14,76 \pm 2,75$ & $29,14 \pm 1,10$ & $67,4 \pm 4,60$ \\
100 & $0,036 \pm 0,12$ & $11,45 \pm 5,77$ & $28,05 \pm 0,76$ & $69,8 \pm 11,39$ \\
\hline ** diferença significativa; ns:F não significativo a 1\% de probabilidade pelo teste F.
\end{tabular}

As determinações de luteína e atividade antioxidante não foram afetadas pelo tempo de armazenamento de 100 dias. Mesmo que não tenha sido detectada diferença significativa ao longo do tempo do conteúdo de luteína e dos valores de atividade antioxidante, podemos observar na Tabela 1 que, quando os valores de luteína aumentam, os valores da atividade antioxidante aumentam, sendo o inverso verdadeiro.

Bernstein et al. (2002) demonstraram que em indivíduos com degeneração macular, a suplementação diária de $4 \mathrm{mg}$ de luteína, resultou em um maior nível de concentração de tal pigmento na mácula, quando comparado ao grupo controle, no qual não foi administrada a 
suplementação. O valor médio de luteína encontrado foi $0,036 \mathrm{mg} / 100 \mathrm{~mL}$ de suco. Dois copos de $300 \mathrm{~mL}$ deste suco suprem 3,6\% das necessidades diárias de consumo de luteína que é de 6 a $20 \mathrm{mg}$ $\operatorname{dia}^{-1}$ (KRINSKY et al., 2003; KRINSKY e JOHNSON, 2005).

$\mathrm{O}$ armazenamento produziu efeito negativo para os teores de compostos fenólicos e de vitamina C, reduzindo-os com o passar dos dias, conforme mostram as Figuras 1 e 2.

Figura 1 - Comportamento do teor de vitamina $\mathrm{C}$ ao longo do tempo de armazenamento $\mathrm{R}^{2}=0,6$

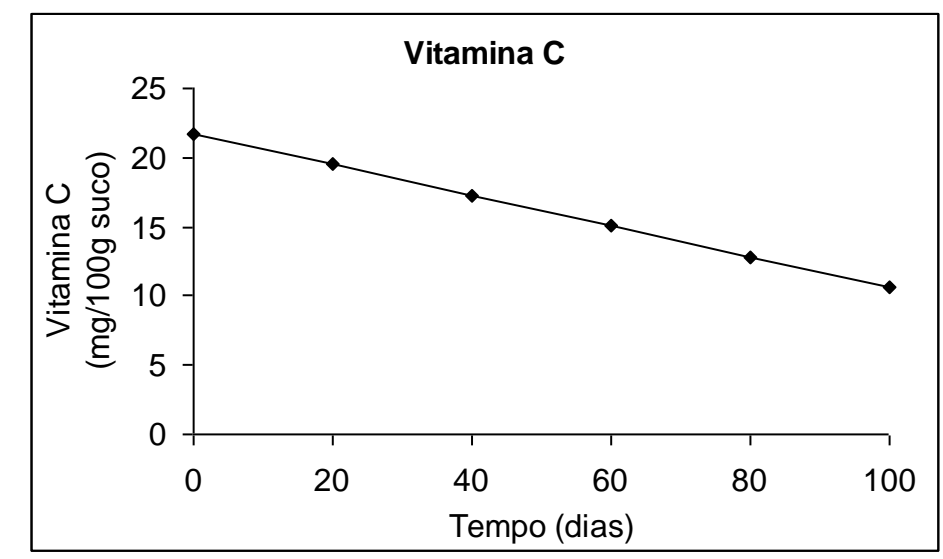

Figura 2 - Comportamento do teor de compostos fenólicos ao longo do tempo de armazenamento $\mathrm{R}^{2}=0,93$

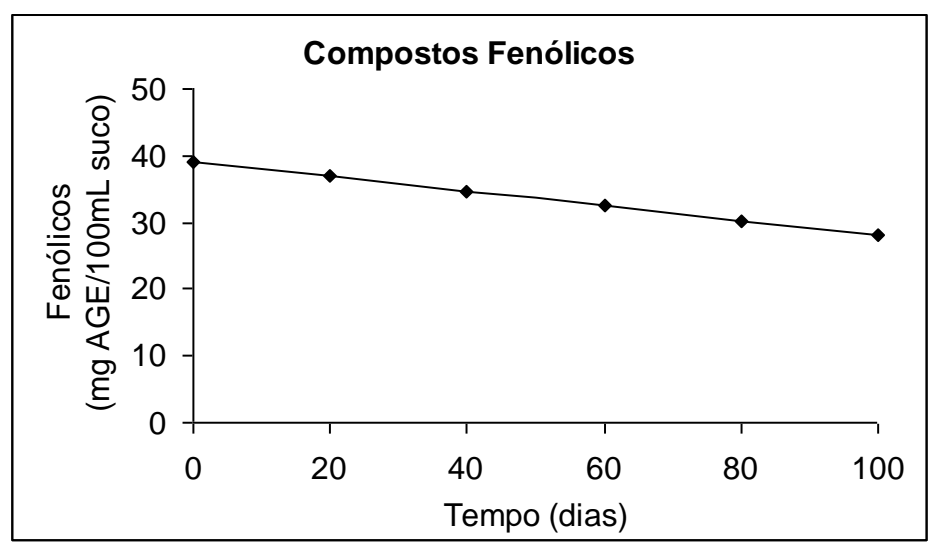

Logo após a fabricação do suco misto, $300 \mathrm{~mL}$ dele possuía cerca de $65 \%$ das necessidades diárias de vitamina $\mathrm{C}$ para um adulto $\left(90 \mathrm{mg} \mathrm{dia}^{-1}\right)$. Ao final dos 100 dias de armazenamento, esse teor representava $38 \%$ das necessidades diárias, sendo considerado alimento fonte de vitamina C. A ingestão de dois copos $(300 \mathrm{~mL})$ do suco misto por dia supriria quase $80 \%$ das necessidades diárias de vitamina $\mathrm{C}$ de um adulto, podendo ser classificado como um alimento fonte deste nutriente. De acordo com a Portaria ${ }^{\circ}$ 27, de 13 de janeiro de 1998, da Agência Nacional de Vigilância Sanitária (ANVISA), para que alimentos líquidos e prontos para consumo sejam considerados fonte de determinado nutriente, deve atingir 15\% da IDR (Ingestão Dietética de Referência) (BRASIL, 1998). 
Apesar da diminuição nos teores de vitamina $\mathrm{C}$ e compostos fenólicos, não houve queda da atividade antioxidante após 100 dias de armazenamento. Os teores de luteína também permaneceram iguais, sugerindo que a luteína é o composto principal na atividade antioxidante. A luteína pode ter sido protegida, pela vitamina $\mathrm{C}$ e pelos compostos fenólicos, da reação com os radicais livres, indicando efeito sinérgico entre os antioxidantes presentes no suco, em que um reage com o radical livre protegendo o outro. Um estudo feito por Tanumihardjo et al (2005) sobre a absorção de luteína, observou que o aumento de luteína no sangue foi significativo quando esse carotenóide foi co-suplementado com vitamina C.

As polpas de acerola e uva se destacaram na avaliação da atividade antioxidante com mais de 90\% de seqüestro de radical DPPH (SAUTTER et al., 2005; VARGAS et al., 2008), enquanto Mantle et al. (2000) encontraram elevada atividade antioxidante nas folhas de Rumex acetosa quando comparada com extrato de Ginkgo biloba, geralmente considerado um potente antioxidante.

O valor médio encontrado para a atividade antioxidante do suco misto foi de $65 \%$ indicando bom poder antioxidante, que foi mantido ao longo do tempo de armazenamento. A vantagem desse resultado está em poder estocar por pelo menos 100 dias o suco, sem o auxílio de refrigeração, diminuindo o custo de armazenamento e, mesmo assim, mantendo os benefícios à saúde do consumidor tão desejados nos sucos de frutas.

\begin{abstract}
Blend composed of $21.8 \%$ pulp of grapes, $14 \%$ pulp of “azedinha” and $4.2 \%$ pulp of acerola, was evaluated as the parameters of lutein, vitamin $C$ and phenolic compounds and antioxidant activity, during 100 days of storage. The levels of vitamin $C$ and phenolic compounds decreased, but the antioxidant activity and content of lutein remained the same, indicating that lutein is the main component responsible for the antioxidant activity of blend, justifying the use of pulp from vegetables into juices. After 100 days of storage, the juice mixture had good antioxidant activity, keeping its bioactive properties of aid in the prevention of diseases caused by free radicals.
\end{abstract}

Key-words: blend; lutein; ascorbic acid, antioxidant activity

\title{
Referências
}

AMARA-MOKRANE, Y.A.; LEBUCHER-MICHEL, M.P.; BALANSARD, G.; DUMÉNIL, G.; BOTTA, A. Protective effects of $\alpha$-hederin, chlorophyllin and ascorbic acid towards the induction of micronuclei by doxorubicin in cultured human lymphocytes, Mutagenesis, v. 11, p. 161-167, 1996. DOI: 10.1093/mutage/11.2.161

BARREIROS, A. L. S.; DAVID, J. M.; DAVID, J. P. Estresse oxidativo: relação entre geração de espécies reativas e defesa do organismo. Química Nova, v. 29, n. 1, p. 113-123, 2006. DOI: 10.1590/S0100-40422006000100021

BEATTY, S.; NOLAN, J.; KAVANAGH, H.; O’DONOVAN, O. Macular pigment optical density and its relationship with serum and dietary levels of lutein and zeaxanthin. Archives of Biochemistry and Biophysics, n. 430, p. 70-76, 2004. DOI: 10.1016/J.ABB.2004.03.015

BERENDSCHOT, T. T. J. M.; GOLDBOHM, R. A.; KLOPPING, W. A. A; KRAATS, J. V.; NOREL, J. V.; NORREN, D. V. Influence of lutein supplementation on macular pigment, assessed with two objective techniques. Investigative Ophthalmology \& Visual Science, v. 41, p. 3322-3326, 2000. 
BIANCHI, M.L.P., ANTUNES, L.M.G. Radicais livres e os principais antioxidantes da dieta. Revista de Nutrição, Campinas, v. 12, n. 2, p. 123-130, 1999.

BRASIL. Agência Nacional de Vigilância Sanitária (ANVISA). Portaria no 27, de 13 de janeiro de 1998. Aprova o Regulamento Técnico referente à Informação Nutricional Complementar (declarações relacionadas ao conteúdo de nutrientes), constantes do anexo desta Portaria. D.O.U. - Diário Oficial da União, de 16 de janeiro de 1998.

BRASIL. Ministério da Agricultura, Pecuária e Abastecimento. Instrução Normativa no 12, de 04 de setembro de 2003. Aprova o Regulamento Técnico para Fixação dos Padrões de Identidade e Qualidade Gerais para Suco e Néctar Tropicais. 09/09/2003.

BRASIL. Ministério da Agricultura, Pecuária e Abastecimento. Lei no 8.918, de 14 de julho de 1994. Estabelece as normas gerais sobre registro, padronização, classificação e, ainda, inspeção e fiscalização da produção e do comércio de bebidas. 15/07/1994.

BRASIL. Ministério da Agricultura, Pecuária e Abastecimento. Secretaria de Relações Internacionais do Agronegócio. Balança Comercial do Agronegócio, 2007. Disponível em: 〈http://www.agricultura.gov.br〉. Acesso em 14/03/2008, 2007.

CAMARGO FILHO, W. P.; MAZZEI, A. R. Hortaliças prioritárias no planejamento da produção orientada: estacionalidade da produção e dos preços. Informações Econômicas, v. 24, n. 12, dez. 1994.

CAMPOS. F. M. Avaliação de práticas de manipulação de hortaliças visando a preservação de vitamina $\mathrm{C}$ e carotenóides. Viçosa, 2006. Dissertação (Mestrado em Ciência da Nutrição) - Departamento de Nutrição Universidade Federal de Viçosa.

DAVIES, N. P.; MORLAND, A. B. Macular pigments: their characteristics and putative role. Progress in Retinal and Eye Research, v. 23, p. 533-559, 2004. DOI: 10.1016/j.preteyeres.2004.05.004.

EDGER, M. C.; GARVEY, D. J., TRUSCOTT T. G. The carotenoids as anti-oxidants -A review. Journal Photochemistry and Photobiology B: Biology; v. 41, p. 189-200, 1997.

ESPíN, J.C.; SOLER-RIVAS, C.; WICHERS, H.J.; GARCÍA-VIGERA, C. Anthocyanin-Based Natural Colorants: A New Source of Antiradical Activity for Foodstuff. Journal of Agricultural and Food Chemistry, n. 48, p. 1588-1592. 2000 .

FREITAS, C.A.S; MAIA, G.A.; SOUSA, P.H.M.; BRASIL, I.M.; PINHEIRO, A.M. Storage stability of acerola tropical fruit juice obtained by hot fill method. International Journal of Food Science and Technology, v. 41, 12161221, 2006. DOI: 10.1111/j.1365-2621.2006.01188.x

HASLAM, E. Natural polyphenols (vegetable tannins) as drugs: possible modes of action. Journal of Natural Products, v. 59, p. 205, 1996. DOI:10.1021/np960040+

KRINSKY, N. I., JOHNSON E. J. Carotenoid Actions and their Relation to Health and Disease. Molecular Aspects of Medicine, v. 26, n. 6, p. 459-516, 2005. DOI: 10.1016/j.mam.2005.10.001

KRINSKY, N. I.; LANDRUM, J. T. ; BONE, R. A. Biologic mechanisms of the protective role of lutein and zeaxanthin in the eye. Annual Review of Nutrition, v. 23, p. 171-201, 2003.

KUHN, R.E., GUZMÁN-SILVA, M.A., GUIMARÃES, J.S.P. Dialquilnitrosaminas e câncer. Revista Brasileira de Cancerologia, Rio de Janeiro, v. 37, n. 1-4, p. 19-26, 1991.

LAJOLO, F. Zeaxantina e luteína reduzem riscos de degeneração macular. Disponível em: http://www.nutricaoempauta.com.br/lista_artigo.php?cod=325. Acesso em: 28/09/2008.

LANDRUM, J. T.; BONE, R. A.; JOA, H.; KILBURN, M. D.; MOORE, L. L.; SPRAGUE, K. E. A one year study of the macular pigment: the effect of 140 days of a lutein supplement. Experimental Eye Research, v. 65, p. 57-62, 1997. DOI: 10.1006/exer.1997.0309

LANGSETH, L. Oxidants, antioxidants, and disease preventions. In BRACCO, U. ILSI Europe concise monograph series. Washington ILSI Pess. 1995. 
MANELA-AZULAY, M.; MANDARIM-DE-LACERDA, C. A.; PEREZ, M. A.; FILGUEIRA, A. L.; CUZZI, T. Vitamina C. Anais Brasileiros de Dermatologia, Rio de Janeiro, v. 78, n. 3, p. 265-274, 2003.

MANTLE, D.; EDDEB, F.; PICKERING, A. T. Comparison of relative antioxidant activities of British medicinal plant species in vitro. Journal of Ethnopharmacology, v. 72, p. 47-51, 2000. DOI: 10.1016/S0378-8741(00)00199-9

MAZZA, G.; FUKUMOTO, L.; DELAQUIS, P.; GIRARD, B.; EWERT, B. Anthocyanins, phenolics, and color of Cabernet Franc, Merlot, and Pinot Noir wines from British Columbia. Journal of Agricultural and Food Chemistry. n. 47, p. 4009-4017, 1999. DOI: 10.1021/jf990449f

MOZAFFARIEH, M.; SACU, S.; WEDRICH, A. The role of carotenoids, lutein, and zeaxanthin, in protecting against agerelated macular degeneration: A review based on controversial evidence. Nutrition Journal, v. 2, n. 20 , 2003.

NACHTIGALL, A. M.; STRINGHETA, P. C; FIDELIS, P. C.; NACHTIGALL, F. M. Determinação do teor de luteína em hortaliças. Boletim CEPPA, v. 25, n. 2, 2007.

NASCIMENTO, W.M. Novos rumos na produção de hortaliças. Embrapa Hortaliças. Disponível em: <http://www.cnph.embrapa.br/public/textos/texto1.html> Acesso em: 11/02/2009.

NISHIKIMI, M.R.; FUKUYAMA, S.; MINOSHIMA, N.; SHIMIZU, K.; YAGI. Cloning and chromosomal mapping of the human nonfunctional gene for L-gulono-gamma-lactone oxidase, the enzyme for L-ascorbic acid biosynthesis missing in man. The Journal of Biological Chemistry; v. 269, n. 18, p. 13685-13688, 1994.

NUNES, I. L.; MERCADANTE, A. Z. Utilização de colunas de fase reversa $C_{18}$ e $C_{30}$ para separação de carotenóides por CLAE. Anais do Congresso Brasileiro De Ciência E Tecnologia De Alimentos, 19, Recife-PE. CD-Rom. 2004.

PUKALSKAS, A.; BEEK, T.A.V.; VENSKUTONIS, R.P.; LINSSEN, J.P.H.; VELDHUIZEN, A.V.; De GROOT, A. Identification of radical scavengers in sweet grass (Hierochioe odorata). Journal of Agricultural and Food Chemistry, n. 50, p. 2914-2919, 2002. DOI: 10.1021/jf011016r

SÁNCHEZ-MORENO, C. Compuestos polifenólicos: efectos fisiológicos. Atividad antioxidante. Alimenaria, p.29-40. 2002.

SAUTTER, C. K.; DENARDIN, S.; ALVES, A. O.; MALlMANN, C. A.; PENNA, N. G.; HECKTHEUER, L.H. Determinação de resveratrol em sucos de uva no Brasil. Ciência e Tecnologia de Alimentos, v. 25, n. 3, p. 437-442, 2005. DOI: 10.1590/S0101-20612005000300008

SILVA, P.C.F. Propriedades antioxidantes in vitro de uva branca e de uva tinta e de seus respectivos vinhos elaborados. Viçosa, 2003, 159 f. Tese (Doutorado em Ciência e Tecnologia de Alimentos) - Departamento de Tecnologia de Alimentos - Universidade Federal de Viçosa.

SOARES, S. E. Acidos fenólicos como antioxidantes. Revista da Nutrição, v. 15, n. 71, 2002.

STAHL, W., SIES, H. Antioxidant defense: vitamins E and C and carotenoids. Diabetes, New York, v. 46, n. 5, p. 14S18S, Supplement 2. 1997.

TANUMIHARDJO, S. A.; LI, J.; DOSTI, M. P. Lutein absorption is facilitated with cosupplementation of ascorbic acid in young adults. Journal of the American Dietetic Association, n. 105, p. 114-1148, 2005. DOI: 10.1016/j.jada.2004.10.011

VARGAS, P. N.; HOELZEL, S. C.; ROSA, C. S. Determinação do teor de polifenóis totais e atividade antioxidante em sucos de uva comerciais Alimentos e Nutrição, Araraquara, v. 19, n. 1, p. 11-15, 2008.

VILELA, D.; ARAUJO, P. M. M. Contribuição das câmaras setoriais e temáticas à formulação de políticas públicas e privadas para o agronegócio. Brasília: MAPA/SE/CGAC, 496 p. 2006.

Trabalho selecionado para apresentação oral durante a VIII SETAL- Semana de Tecnologia de Alimentos- Câmpus Ponta Grossa- Universidade Tecnológica Federal do Paraná- 01 a 03 de junho de 2011. Suplemento especial da RBTA. 